\title{
A TÉCNICA DO VÔO HUMANO E O DIREITO (*)
}

\author{
PAULO ERNESTO TOLLE \\ (Professor de Direito no Instituto Tecnológico de \\ Aeronáutica)
}

"O assunto para o qual chamo hoje a atenção dos senhores, constitui completa novidade em direito internacional, e num futuro próximo será de grande importância, quer em tempo de paz, quer na guerra. Acabamos de atravessar o portal de uma nova descoberta e aprendemos agora que o ar pode ser usado como meio de trânsito de um para outro lugar da superfície da terra. A forma pela qual melhor poderemos utilizar comercialmente êsse conhecimento, ainda não foi tornada perfeita; muito resta a fazer, antes que possamos transportar passageiros ou mercadorias com qualquer margem de segurança ou regularidade. Mas, pelo que já foi realizado, temos boas razões para crer que o uso do ar para fins comerciais é mera questão de tempo".

Com essas palavras se iniciou a aula de 26 de Outubro de 1912, de Sir H. Erle Richards, professor de Direito Internacional e Diplomacia, na Universidade de Oxford.

O calendário do vôo humano já registrava então, entre outras boa;

1709 - ascenção do balão de Bartolomeu de Gusmão, em Lis-

1783 - primeira viagem aérea, em balão, de Pilatre de Rosier e - Marquês de Arlandes, em Paris;

1784 - primeira viagem aérea internacional, em balão, sôbre a Mancha, feita por Blanchard;

1901 - demonstração prática da dirigibilidade dos aerostatos, por Santos Dumont.

(*) Conferência na Faculdade de Direito de Baurú, em 20.10.1960 
Sete anos após aquela, em 1919, a Sociedade Parman inaugura serviço de transporte aéreo comercial de passageiros, em linha internacional, entre Paris e Londres. Á era de pioneirismo, entre 1919 e 1931, dos raides sensacionais de Lindbergh e outros, segue-se o período de desenvolvimento da ligação aérea comercial transoceânica, a partir de 1933. Em 1957 entra em órbita o Sputnik I. E ainda não faz um ano, o Lunik II atingiu a lua.

Assim como em poucos anos se desenvolveu o transporte "de um para outro lugar da superfície da terra" através da camada atmosférica, o vertiginoso progresso tecnológico nos permite, adaptando aos nossos dias a previsão acertada do professor Richards, dizer que - temos boas razões para crer que o uso do espaço supra-atmosférico para fins comerciais é mera questão de tempo, e provàvelmente de pouco tempo.

E como qualquer atividade do homem só se poderá exercer normalmente sob a égide da lei, imperioso se tornou o estudo, a formulação e o equacionamento das questões jurídicas já resultantes ou que venham a resultar do novo empreendimento.

Daí o aplauso que merecem iniciativas como a da douta Congregação da Faculdade de Direito de Baurú, que se inscreverá naquele calendário da aviação como pioneira do ensino do direito do espaço em nosso país.

Interêsses estratégicos, políticos, econômicos, sociais e científicos, dos Estados, no espaço além da atmosfera, têm levado os especialistas à procura de preceitos jurídicos já existentes que se possam aplicar à nova atividade do homem, ou à criação de novo sistema legal que discipline adequadamente 0 assunto.

Reabriu-se a discussão sôbre a limitação da soberania estatal em altura; debate-se a teoria do consentimento tático, em face do lançamento de satélites no Ano Geofísico Internacional; estudam-se os problemas de identificação de espaço-naves, composição de danos na superfície, interdição do uso militar do espaço; propõe-se a internacionalização do "outer space"; discute-se a denominação a ser dada ao novo ramo do direito; o já se cogita de subdividir um Direito Cósmico em Direito Transaéreo, Direito Interplanetário e Transdireito. Estudase, principalmente, a elaboração de regras para a utilização do espaço que assegurem um mínimo de garantia aos interêsses dos Estados o das pessoas subjacentes.

Tais temas se incluem por certo no programa do curso ora sendo ministrado nesta Casa por mestres que os dominam com segurança, e não seria prudente a um modesto estudioso do Direito Aeronáutico tentar voar tão alto.

Com o exemplo de Ícaro na memória, mantenham-nos mais próximos da terra, em ambiente a que estejamos afeitos. E é assim que 
convido êste seleto auditório a despir as vestes espaciais e fazer comico, num "Forde-bigode" DC-8 ou Boeing 707, ligeiro "sightseeing tour" pelo direito aeronáutico.

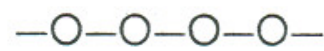
ção?

Mas, que é direito aeronáutico, e qual o seu campo de aplica-

Tentaremos alinhar alguns dos vários problemas relacionados com as indagações propostas, reunindo-os, sem a pretensão de esgotar - assunto, sob três tópicos gerais: $10^{\circ}$ - a situação jurídica da via utilizada; $2 .^{\circ}$ - a caracterização legal do instrumento utilizado; $3^{\circ}$ questões de direito decorrentes da operação de aeronaves.

No primeiro grupo se contêm os temas relativos à propriedade e à soberania.

Quanto à propriedade, lembremos que ao possuidor de trato de terra se atribuia o direito de uso e gôzo irrestrito e sem limitação em altura ou profundidade. O conceito expresso na máxima "cujus est solus ejus est ad coelum et ad inferos" se afirmara no Código Napoleão, cujo artigo 552 inscreve o princípio do direito de propriedade sôbre o sub-solo e o espaço.

A aplicação rígida da máxima do glosador Acúrcio se afigurou inexequível, no entanto, quanto a utilização prática do espaço como verdadeira estrada aérea impôs a constituição de nova forma de direito de trânsito público.

Efetivamente, aquêle direito ilimitado se estabelecera na presunção da limitação da capacidade de utilizar o ar. Era lógico que o proprietário do solo seria dono do espaço aéreo que pudesse utilizar, e que as possíveis violações do seu direito só poderiam ocorrer em altura relativamente pequena e se caracterizariam pela interferência prejudicial ao uso e aproveitamento direto do solo.

A primeira brecha na fortaleza do direito de propriedade, ainda que tendo por fundamento a teoria do abuso de direito, e não a da contestação da máxima de Acúrcio, foi a sentença do Tribunal Civil de Compiègne, em 1913, quando o cidadão Coquerel erigiu postes, com pontas de ferro, em seu terreno, danificando dirigiveis do cidadão Bayart, cujo campo de experiências com balões era contíguo:

"... Comete abuso de direito o proprietário que eleva sôbre seu terreno obras pretensamente defensivas... sob o pretexto de se proteger da vizinhança de um construtor de balões dirigíveis, quando na realidade as instalou no propósito de danificar os aparelhos do seu vizinho..."

O mesmo princípio de rejeição das chamadas "spite structures" - obstáculos erigidos por picardia - é afirmado em decisões de tribunais norte-americanos, como no caso de lowa City v. Tucker, em 
1935, em que a Côrte Distrital de Johnson Country proibiu ao proprietário erigir estruturas ou plantar árvores "de pique", a mais de 25 pés de altura, na vizinhança de um aeroporto, pois tal atividade não constituia uso e gôzo apropriados da propriedade e perturbava o interêsse público.

No mesmo sentido se orientariam, necessàriamente, juízes e tri bunais e se elaborariam novas leis, pesando com cuidado os interêsses públicos e os particulares e mantendo o equilíbrio característico do direito - entre uns e outros. Firmou-se, assim, o entendimento de que a passagem de aeronaves sôbre propriedades privadas seria livre, observados os regulamentos de vôo e assegurada às pessoas na superfície a reparação em caso de lesão.

O caráter de utilidade pública do transporte aéreo logo se definiu, justificando também, ainda em relação à propriedade privada, a desapropriação desta, para a instalação do aeródromos, e o zoneamento das áreas vizinhas a aeroportos, com restrições de altura e de utilização de instalações.

Quanto à soberania, entre os direitos de um Estado sempre se entendeu incluído o de determinar se podem ou não os estrangeiros comerciar em seu território, nêle ingressar e por êle passar.

Cêrca de 500 anos antes de nossa era, quando incipiente ainda era o poderio romano, Roma e Cartago concluiram um tratado delimitando a esfera de ação permitida às náus de Roma: não poderiam navegar além de dado ponto - uma declaração implícita da extensão das águas territoriais cartaginesas; aquelas que aportassem a terras sob o contrôle de Cartago só o poderiam fazer para reparos e reabastecimento; definiam-se as colônias cartaginesas com as quais os romanos poderiam livremente comerciar; e fiscalizava-se o exercício dêsse comércio.

Aí temos, provàvelmente, a fonte mais remota da Convenção de Aviação Civil Internacional de Chicago, de 1944, e dos acordos bilaterais modernos relativos ao transporte aéreo comercial.

Tais preceitos de direito internacional já se haviam estabelecido antes que o espaço aéreo se houvesse tornado uma das vias de transporte.

Porém, enquanto que, no tocante à propriedade, já se afirmava, peremptório, o conceito de sua extensão "usque ad coelum", o problema do prolongamento vertical das fronteiras era até então pràticamente inexistente.

Daí a acirrada controvérsia entre juristas, face ao fato nôvo, desde os extremados defensores da tese da liberdade absoluta dos ares, com fundamento em analogia entre espaço e alto mar, até aos que iam buscar na antiga máxima de Acúrcio, e mesmo nos textos das Insti- 
tutas, do Digesto e do Código de Justiniano, relativos aos interêsses no "aer" ou no "coelum", a origem do direito de soberania ilimitada do Estado sôbre o espaço aéreo.

Observe-se, contudo, que tal debate se cingia aos doutrinadores, e que nenhum país oficialmente adotou a teoria da liberdade total ou parcial; pelo contrário, o direito positivo, ao se manifestar, o fêz, tanto interna como internacionalmente, no sentido da afirmação do princípio de que a noção de território é tridimensional, estando o espaço aéreo sob a soberania do Estado subjacente.

Atos isolados - como o regulamento da Polícia de Paris, em 1784, sôbre o uso de balões; a carta de Bismarck ao govêrno francês, em 1870, a respeito do sobrevôo das linhas prussianas por balões franceses; a lei inglesa de navegação aérea, de 1911; o acôrdo francoalemão relativo ao vôo entre os dois países, de 1913 - já constituiam demonstrações do direito de soberania. O mero fato de um Estado regular, em sua lei, o uso de seu espaço aéreo, constitui manifestação evidente de sua soberania sôbre tal espaço.

Confirmou-o em definitivo a Convenção relativa à regulamentação da navegação aérea, assinada em Paris a 13 de Outubro de 1919, cujo texto, a êsse respeito, é repetido no artigo $1 .^{\circ}$ da Convenção de Chicago, de 7 de Dezembro de 1944. E idêntica declaração tem sido incorporada à lei aeronáutica de grande número de países.

No tráfico conduzido na superfície, como já observamos, têm us estrangeiros um direito imperfeito. A noção de soberania sôbre o espaço atmosférico importa, pois, rigorosamente, no poder de proibir a deronaves estrangeiras a utilização do espaço aéreo nacional - restrição esta que resultaria em irremovível obstáculo à navegação aérea, que é eminentemente internacional.

Assim como o direito do proprietário no solo sofrera revisão diante da atividade aeronáutica, parecia também necessário que o Estado renunciasse, ainda que parcialmente, à soberania, ou que se recorresse a uma fórmula, internacionalemnte aceita, autorizando o tráfego livre ou regulamentado.

Para a discussão do assunto reuniram-se em Paris, em 1910, representantes de 19 Estados europeus, em conferência internacional.

Nota pitoresca dos trabalhos preparatórios deve ser mencionada: ao ser consultado pelo embaixador francês na Inglaterra sôbre quais as nações que deveriam ser convidadas, opinou o Foreign Office no sentido de se dispensar a convocação dos Estados Unidos da América - porque, estando a tão grande distância, não participavam dos problemas do vôo internacional...

Conquanto da conferência não resultasse acôrdo internacional, o projeto de convenção então preparado serviu de valiosa fonte para a 
Convenção de Paris de 1919, e muitos dos trabalhos apresentados em 1910 influenciaram decisões futuras, valendo citar o ante-projeto alemão, que previa condições para o estabelecimento de linhas internacionais e para a cabotagem, que tiveram reflexo na Convenção de Chicago, de 1944.

A Convenção de Paris de 1919, como já vimos, consagrou o princípio de soberania; ao mesmo tempo, visando o estímulo à navegação aérea internacional, instituiu, para vôos não comerciais, o direito de passagem inocente $\mathrm{em}$ tempo de paz. Não se cogitou a fundo do comércio aéreo internacional, que ainda era inexpressivo e foi deixado à regulamentação através de acordos bilaterais.

Quando a Convenção de Chicago, de 1944, foi elaborada, já se estabelecera sòlidamente o transporte aéreo internacional. No entanto, a Convenção, além de renovar a declaração de soberania, ainda manteve a proibição do uso econômico do espaço aéreo nacional por emprêsa estrangeira, a não ser mediante autorização e segundo as condições estipuladas pelo Estado sobrevoado, e apenas concedeu o direito de sobrevôo e pouso a aeronaves não empregadas em serviço comercial regular.

A situação jurídica das vias utilizadas pela aviação - a terra firme onde se inicia e na qual deve terminar o vôo, e o espaço aéreo através do qual se movimenta a aeronave - se caracteriza, pois, em síntese, pelo enfraquecimento do direito do proprietário no solo e pelo robustecimento do direito do Estado sobrevoado.

Consideremos agora o tópico concernente à caracterização legal do instrumento utilizado - a aeronave.

As principais questões dizem respeito à nacionalidade da aeronave e à lei $\epsilon$ jurisdição aplicáveis a fatos ocorridos ou atos praticados a bordo da aeronave.

Quanto à nacionalidade, ao tempo dos primeiros balões ainda não se cogitava do assunto.

Em Janeiro de 1785, o mesmo Blanchard a que aludimos ao alinhar algumas datas históricas da aviação, voou de Denver a Calais sôbre a Mancha, em companhia de Jeffries, cidadão inglês de origem norte-americana. Ao iniciarem o vôo - o francês levava sua bandeira e Jeffries a bandeira inglêsa, porém não se caracterizara o balão como tendo nacionalidade. Até o fim do século XIX, quer em vôos individuais, quer em operações militares, e também nos estudos sôbre o uso do espaço aéreo, não se havia levantado a questão.

O primeiro a considerá-la foi Paul Fauchille, em 1901, em sua monografia "Le domaine aérien et le régime juridique des aérostats": a aeronave, como os navios, deve ter nacionalidade. No ano seguinte, em seu relatório ao Instituto de Direito Internacional, propunha a clas- 
sificação das aeronaves em duas categorias - públicas e privada - e que cada aeronave levasse a bandeira de um só Estado. Propunha, ainda, que a aeronave privada fôsse registrada no Estado que pertencesse.

Traçou-se desde logo a analogia com o direito marítimo, fonte das mais importantes do direito aeronáutico: entre o navio e o Estado há um vínculo, segundo o qual um país considera o navio como seu e não de outro Estado qualquer. Compara-se o navio a uma pessoa, apesar de ser coisa. Dá-se-lhe individualidade. E a atribuição de nacionalidade é o fundamento para a intervenção e a proteção, de parte do Estado; - submete-se o navio ao contrôle de um Estado e às sanções de suas leis, e dêle recebe proteção contra abusos que, de parte de pessoas de outros Estados, possa sofrer. A nacionalidade do navio é condição para a utilização pacífica dos mares. E assim como a necessidade de disciplinar o tráfego marítimo - principalmente on. de êste não está sob a soberania de nenhum Estado, no alto mar é uma das principais razões da atribuição de nacionalidade ao navio, com mais fortes motivos deve aquela ser estendida à aeronave, face à sua capacidade de cruzar mares, continentes, fronteiras.

A idéia da nacionalização da aeronave foi aceita na Conferência de Paris de 1910 e inscrita em leis nacionais como o British Aerial Navigation Act de 1911. Durante a primeira Guerra Mundial as aeronaves foram consideradas como tendo nacionalidade, e o princípio se incorporou definitivamente ao direito internacional com a Convenção de Paris de 1919.

Conforme o artigo $7 .^{\circ}$ da Convenção, para registro de uma aeronave em um Estado, exigia-se pertencesse a nacionais dêsse Estado. O preceito foi, porém, modificado pelo Protocolo de 15 de Junho de 1929 e deixadas a critério de cada país as condições de rer gistro. Disso resultou a ausência de uniformidade quanto aos requisitos para registro e nacionalidade, com consequências importantes no porblema do contrôle de linhas aéreas internacionais.

Aceito o princípio de que a aeronave tem nacionalidade outros problemas se apresentam correlatos, como o da iurisdição quanto às ocorrências verificadas a bordo.

Em aula de 15.11.57, no Instituto of Air and Space Law da Universidade McGill, o professor Eugène Pépin relacionou, entre outros, os seguintes acontecimentos:

a) em 1889, registrou-se o primeiro nascimento de uma pessoa a bordo de aeronave;

b) em 1928, foi encontrado, em alto mar, entre a França e a Inglaterra, o corpo de um milionário belga desaparecido durante um vôo entre Londres e Paris, recusando-se as autoridades britânicas a conduzir as investigações policiais necessárias; 
c) em aeronave suiça, voando de Zurich para os Estados Unidos da América, um pastor norte-americano celebrou um casamento de norte-americanos;

d) em aeronave holandesa, voando entre Londres e Berlim um cidadão francês e um belga firmaram contrato comercial;

e) em aeronave voando de Pôrto Rico para New York, com 60 passageiros a bordo, dois dêstes, Cordova e Santana, embriagados, promoveram conflito de que resultou a queda do avião em alto mar; o tribunal norte-americano a que foi sujeito o caso considerou Cordova culpado mas deixou de determinar a execução, por se tratar de fato ocorrido fora da jurisdição nacional.

Novamente neste setor discutem os doutrinadores, a favor da aplicação do princípio da territorialidade - a lei e a jurisdição devem ser as do país onde está a aeronave - ou do princípio da nacionalidade - lei do país da bandeira da aeronave - ou de combinações dos dois sistemas, como a aplicação da teoria da nacionalidade salvo quando violados pelos atos a bordo os interêsses do Estado sobrevoado; e ainda outras teses, como a da jurisdição do país de onde partiu a aeronave ou a do Estado onde é feita a primeira sterragem.

O terceiro grupo de problemas, criados pelo vôo humano diz respeito às consequências jurídicas da utilização da aeronave. $O$ primeiro dêles compreende as questões relativas à responsabilidade do operador da aeronave.

A revisão da teoria clássica de responsabilidade fundamentada na culpa teve, no advento da aviação, mais uma justificativa.

Os princípios jurídicos normalmente aplicáveis ao transporte de superfície não se ajustavam à nova modalidade de veículo que é a aeronave.

Principalmente na fase inicial da aeronáutica, os chamados "ris$\cos$ do $\operatorname{ar}^{\prime \prime}$ são voluntàriamente assumidos pelo passageiro, que, conhecendo-os, opta por essa forma de locomoção, apesar dêles. Por outro lado, enquanto que os motivos de não cumprimento da obrigação contratual de levar o passageiro ou a carga, incólumes, ao ponto de destino, têm sua constatação mais fàcilmente estabelecida no transporte de superfície, a verificação da causa de um acidente aéreo nem sempre pode ser feita.

Criou-se, em consequência, um regime de responsabilidade que, por um lado, é limitada em quantia pré-estabelecida, e que, por outro lado, gera para o transportador uma presunção de culpa, a êle cabendo o ônus da prova liberatória.

Também quanto a danos causados a terceiros na superfície (que não participam, quer como transportador quer como passageiro ou expedidor de carga, do contrato de transporte) instituiu-se a doutrina 
da responsabilidae baseada no risco, porém, também limitada na compensação. Cumpre indenizar aquêle que é prejudicado pelo fato aviatório. Mas a aviação, ainda que não interessando diretamente o terceiro na superfície', traz-lhe indiretamente o benefício que todo nôvo invento útil incorpora à sociedade - e não deve então a indenização corresponder ao prejuízo total eventual, o que tornaria a emprêsa aeronáutica econômicamente impossível, e sim ser limitada.

Ainda quanto às questões decorrentes da utilização da aeronave, devem-se mencionar os problemas que dizem respeito à intervenção do Estado nessa atividade.

$E^{\prime}$ a aeronave, como o próprio sentido etimológico do vocábulc indica, instrumento de navegação pelos ares. E dentro do conceito amplo de navegação aérea se incluem tanto a utilização do avião pa- como seu emprêgo comercial em trabalhos de agricultura, aerofotogrametria, propaganda e outros e, principalmente, no transporte comercial pròpriamente dito.

É óbvio que principalmente a última atividade citada - o transporte comercial de pessoas ou coisas - constitui indústria de interêsse coletivo em qualquer Estado, levando êste a nela intervir em maior ra fins particulares - esporte, turismo, transporte sem fins lucrativos ou menor grau, seịa considerando-a serviço público a ser por êle próprio executado diretamente ou por concessão, seja declarando-a de utilidade pública e nela interferindo através da fiscalização e regulamentação.

Mas também a utilização do avião por particulares, ou em atividades comerciais cuja re'evância não justifiquem sua inclusão entre os serviços públicos, deve ser sujeita à autoridade estatal. Porque envolve problemas que ao Estado cabe regular, como os de tráfego, repressão ao contrabando, saída de pessoas do país ou sua entrada neste, segurança pública e defesa nacional.

Os característicos peculiares à aviação impõem, portanto, que, mais do que em outros setores da iniciativa e do trabalho privado, a ingerência, contrôle e fiscalização do Estado se façam sentir mais diretamente e com maior intensidade.

O surgimento da máquina voadora suscitou, como vimos em rápido e incompleto bosquejo, novos problemas jurídicos, consequentes de atividades relacionadas com os mais variados ramos do direito - o interno e o internacional, o público e o privado, o donțtitucional, o administrativo, o comercial, o penal - podendo-se dizer, com AMBROSINI, que êsses novos problemas cobrem

"como que todo o direito reduzido em escala, ou seja, quase todo o direito circunscrito ao seu objeto: a aviação" (1).

(1) Antonio Ambrosini, "Instituciones de derecho de la aviacion", 1946, Tomo I. 
Para equacionar tais problemas, cuịa solução não se poderia buscar nas fórmulas jurídicas tradicionais, formularam-se novas normas, e assim se esboçou a configuração de um nôvo ramo especializado da árvore jurídica - o Direito Aeronáutico.

Muitas são as definições com que os especialistas procuram caracterizar o direito aeronáutico, e citaremos aqui apenas duas, que nos parecem de maior precisão. Considera-o LEMOINE (2) o ramo do direito que regulamenta a circulação e a utilização das aeronaves, assim como as relações a que elas dão causa. E PÉPIN (3) ensina que o objeto do direito aeronáutico é regulamentar a circulação, a navegação e o uso da aeronave, bem como os direitos e obrigações resultantes.

Vemos, pois, que o conceito de aeronave constitui o ponto central para a caracterização do Direito Aeronáutico e do seu campo de aplicação.

Deve o têrmo "aeronave" ser empregado sem consideração de seu sentido etimológico? Em tal caso se estenderia a qualquer veículo capaz de ser dirigido no espaço aéreo ou além do espaço aéreo - e teríamos o direito do espaço incluído entre os capítulos do direito aeronáutico.

Circunscrever-se-á o vocábulo às chamadas aeronaves convencionais, "air breathing"? Impõe-se, então, um novo tipo de legislação e acordos internacionais para regulamentar o transporte supra-atmosférico.

Qualquer que seja, porém, o instrumento de "vôo" inventado e utilizado pelo homem, qualquer que seja sua velocidade, autonomia ou destino, estará êle sujeito à lei do homem; e não importa quais distâncias atinja, não deverá desligar-se do regime jurídico dêste planeta.

Mas, já sinto rarefeito o ar; tratemos de conduzir de volta êsses pacientes passageiros à plataforma de onde espaçonautas mais competentes e arrojados os conduzirão de novo "ad astra".

(2) Lemoine, Traité de droit aérien, 1947, p. 3.

(3) Eugène Pépin, aula, Universidade McGill, 25.10.57. 